\title{
RELAÇÃO ESTADO - SOCIEDADE CIVIL NAS POLÍTICAS EDUCACIONAIS PARA A EDUCAÇÃO DE JOVENS E ADULTOS (EJA)
}

\author{
LATION STATE - CIVIL SOCIETY IN EDUCATION POLICIES FOR THE EDUCATION OF \\ YOUTH AND ADULT (EJA)
}
RELACIÓN DEL ESTADO - LA SOCIEDAD CIVIL EN LA POLÍTICA DE LA EDUCACIÓN PARA LA JUVENTUD Y LA EDUCACIÓN DE ADULTOS (EJA)

\author{
Elielma Velasquez de Souza Maiolino
}

\begin{abstract}
RESUMO: Este artigo tem como objetivo apresentar as discussões em torno da relação Estado - sociedade civil na elaboração, implementação e acompanhamento das políticas educacionais para a Educação de Jovens e Adultos (EJA) no Brasil e o financiamento dessa modalidade de ensino, fortalecida por meio das parcerias entre o público, o privado e organizações não governamentais. Para a realização da pesquisa foram utilizados, como dados primários, os documentos produzidos e publicados pelo Ministério da Educação (MEC) e como fontes secundárias utilizou-se as produções acadêmicas que trataram da temática e que ajudaram na compreensão das categorias de análise: Estado, trabalho, capital e política pública de corte social. Os resultados podem ser assim sintetizados: se, antes, a participação da sociedade civil se circunscrevia aos processos de democratização do Estado, pelo seu papel de controle e direcionamento dos serviços públicos, neste momento ela é conduzida a colaborar diretamente com a oferta dos serviços educacionais, pela lógica de diminuição das responsabilidades do Estado. Portanto, as políticas educacionais estão postas mais como formalização de direito ao acesso a essa população, do que como forma de qualificar as especificidades da educação de jovens e adultos em seus diversos contextos socioculturais para o mundo do trabalho.
\end{abstract}

PALAVRAS-CHAVE: Educação de Jovens e Adultos. Políticas educacionais. Parcerias.

ABSTRACT: This article aims to present discussions around the relation state - civil society in the formulation, implementation and monitoring of educational policies for the Education of Youth and Adults (EJA) in Brazil and the funding of this type of education, strengthened through partnerships between the public, the private and nongovernmental organizations. To conduct the survey were used as primary data, documents produced and published by the Ministry of Education (MEC) and as secondary sources were used academic productions that addressed the thematic and helped in the understanding of the categories of analysis: State, labor, capital and public policy in the social sector. The results can be summarized as follows: if before the civil society participation was limited to State democratization processes, for its role of control and direction of public services, this time it is conducted to collaborate directly with the provision of educational services, by the reduction logic of State responsibilities. Therefore, educational policies are put more as formalization of the right to the access to that population, than as a way of qualifying the specifics of the education of youth and adults in their various socio-cultural contexts for the world of work.

KEYWORDS: Youth and Adult Education. Educational policy. Partnerships.

RESUMEN: Este artículo tiene como objetivo presentar los debates referentes a la sociedad estatal - civil en la formulación, aplicación y seguimiento de las políticas educativas para la Educación de los Jóvenes y Adultos (EJA) en el Brasil y en la financiación de este tipo de educación, fortalecida a través de asociaciones entre el sector público y las organizaciones privadas y no gubernamentales. Para realizar el estudio se utilizaron como datos primarios, los documentos producidos y publicados por el Ministerio de Educación (MEC) y como fuentes secundarias se utilizaron

\footnotetext{
${ }^{1}$ Doutora em Educação, Professora do Curso de Pedagogia da Faculdade Salesiana de Santa Teresa - Corumbá, MS - Brasil. Email: elimaiolino@gmail.com
}

Recebido em: 14/11/2014 - Aceito em: 09/03/2015

\begin{tabular}{l|l|l|l|l|l|l} 
(C) ETD - Educ. Temat. Digit. & Campinas, SP & v.17 & n.1 & p.75-87 & jan./abr.2015 & ISSN 1676-2592
\end{tabular}


producciones académicas que abordaron la temática, lo que ayudó en la comprensión de las categorías de análisis: el Estado, el trabajo, el capital y la política pública en el sector social. Los resultados se pueden resumir de la siguiente manera: si antes, la participación de la sociedad civil se circunscribia a los procesos de la democratización del Estado, debido a su papel de control y de direccionamiento de los servicios públicos, en este momento, ella es conducida a colaborar directamente con la oferta de los servicios educacionales, la lógica disminución de las responsabilidades del Estado. Por tanto, las políticas educacionales están puestas más como formalización de derecho al aceso de esa populación, está propuesta más como formalización del derecho al acceso a esta población, de que una forma de calificar las especificaciones de la educación de los jovenes y adultos en sus diversos contextos socioculturales para el mundo del trabajo.

PALABRAS CLAVE: Educación de Jóvenes y Adultos. Las políticas educativas. Asociaciones.

\section{A PARTICIPAÇÃO DA SOCIEDADE CIVIL NA OFERTA DA EJA}

Embora a Educação de Jovens e Adultos (EJA) seja reconhecida como um direito para as pessoas jovens e adultas que não tiveram oportunidade de realizar sua escolaridade, esse direito só foi formalizado em lei, como dever de oferta obrigatória pelo Estado brasileiro, a partir da Constituição de 1988, e reafirmado pela Lei de Diretrizes e Bases da Educação Nacional $n^{\circ}$ 9.394/96. A pesquisa procurou mostrar que o papel da educação, nesse contexto, foi além da preparação para o mundo do trabalho. $\mathrm{O}$ papel foi o de formalizar o direito à educação para essa parte da população excluída.

No Brasil, os estados e os municípios são os principais entes federados a desenvolver programas de alfabetização e de ensino fundamental de jovens e adultos. No decorrer dos anos 1990, os direitos de cidadania da população jovem e adulta à alfabetização e ao ensino fundamental (afirmados na Constituição Brasileira de 1988) vêm sendo foco de um processo da reforma educacional.

O documento intitulado Plano da Reforma do Estado, elaborado pelo Ministério da Administração e Reforma do Estado (em 1995, no governo Fernando Henrique Cardoso), afirma que a reforma do Estado está ligada à transferência para o setor privado das atividades que podem ser controladas pelo mercado. Nesse período, houve a ampliação do quadro de interlocutores sociais (formados por movimentos sociais e entidades parceiras denominadas "terceiro setor" no país, que assumiram, desde então, ações relativas à educação de jovens e adultos, predominantemente circunscritas a concepções e práticas que concorrem para que "[...] a lógica do capital permaneça intacta como quadro de referências orientador da sociedade" (MÉSZÁROS, 2007, p. 207) e coadunadas com as novas formas de sociabilidade requeridas pelo capital à classe trabalhadora.

O que se tem concretizado em termos de políticas públicas para a EJA refere-se à descentralização das responsabilidades, promovendo uma ampla participação de todos os setores da sociedade. No entanto, não se apresenta uma proposta transparente em relação à definição dos recursos que viabilizam os gastos e à prestação de contas. 
Assim,

[...] passa a ser construído um espaço denominado de esfera pública não-estatal, que abarca um conjunto de organizações da sociedade civil, entre elas ONGs, que vêm atuando no desenvolvimento de projetos, na prestação de serviços sociais e assessoria a organizações populares de defesa de direitos, e está relacionado à desregulamentação do papel do Estado na economia e na sociedade. O Estado transfere parte de suas atribuições para as comunidades organizadas, em ações de parceria com as ONGs (DELUIZ; GONZALEZ; NOVICKI, 2005, p. 2).

Enfatizando as parcerias, o atendimento da EJA ocorre basicamente de forma descontínua e diversificada: entre os diversos programas e projetos, existem ações desenvolvidas tanto no âmbito dos poderes públicos quanto no da sociedade civil.

Para Di Pierro (2001, p. 330), a participação considerável e atuante das ONGs implica reduzir " [...] o cidadão à condição de consumidor e as organizações sociais à condição de prestadoras de serviços públicos, abstraindo totalmente as questões ético-políticas implicadas no conceito de esfera pública democrática". Além disso, a transferência das responsabilidades dos serviços educacionais para a sociedade civil afetou o financiamento estatal desses serviços por meio de fundos públicos. Esses fundos públicos têm se afinado muito mais com as demandas do sistema econômico externo do que com a reprodução da força produtiva interna, fazendo tonificar as desigualdades sociais (OLIVEIRA, 1988).

Dessa forma, as políticas sociais assumiram novas características com a reforma empreendida no âmbito do Estado brasileiro nos anos 1990, ou seja, foram formuladas como parte da estratégia de construção de uma nova hegemonia neoliberal, cujos princípios pautam-se na lógica do livre mercado, na competitividade e na produtividade, tendo em vista a maximização do lucro.

Se o objetivo é racionalizar os recursos e esvaziar o poder das instituições públicas, então "[...] a responsabilidade pela execução das políticas sociais deve ser repassada para a sociedade: para os neoliberais, por meio da privatização (mercado), e para a Terceira Via pelo público não estatal (sem fins lucrativos)" (PERONI; ADRIÃO, 2006, p. 14).

As ONGs (algumas de natureza filantrópica e assistencial) foram, então, convocadas a participar diretamente de ações, anteriormente implementadas pelos setores públicos, no atendimento aos direitos constitucionais à educação. Sobre as concepções de educação apresentadas em programas e projetos desenvolvidos pelas ONGs, observa-se que se fundamentam em distintas abordagens teórico-metodológicas da relação entre o trabalho e a educação, trazendo modificações nas práticas pedagógicas concretamente implementadas.

$\mathrm{Na}$ análise de Montaño (2002, p. 17), as ações da sociedade civil, a qual se constitui em terceiro setor, têm o "[...] papel central no processo de desregulação e (contra) reforma estatal, na reestruturação produtiva, na flexibilização produtiva e comercial, no financiamento ao capital, particularmente financeiro". Ou seja, suas ações propiciam, 
[...] a diminuição dos custos da atividade social - não pela maior eficiência dessas entidades, mas pela verdadeira precarização, focalização e localização destes serviços, pela perda de suas dimensões de universalidade, de não contratualidade e de direito do cidadão - desonerando o capital. (MONTAÑO, 2002, p. 47).

Por essa razão, Montaño (2002) chama a atenção para a instrumentalização e a funcionalidade do terceiro setor para com o projeto neoliberal. Ele afirma que o sistema capitalista, na sua fase madura, transforma todas as relações sociais, indivíduos, práticas, valores, enfim, todas as esferas da vida social, em meios para a acumulação capitalista. A precarização do trabalho, assim como a informalidade, teve um crescimento acirrado no país em decorrência, por exemplo, dos baixos salários, da perda de direitos, do enfraquecimento dos sindicatos.

Montaño (2002) enfatiza que as políticas sociais, mantidas sob o controle do Estado, são alteradas, uma vez que são transferidas para os níveis locais das esferas de governos, passando a ser mais focais e menos universalistas. Portanto, o que está em foco "não é o âmbito das organizações, mas a modalidade, fundamentos e responsabilidades inerentes à intervenção e respostas para a questão social" (Idem, p. 185). Sobre isso, Peroni, Oliveira e Fernandes (2009, p. 773-774) argumentam que:

O que se conclama desde então é uma participação do tipo voluntariado, da ajuda mútua dos "amigos da escola", enfim, das parcerias, uma vez que nestas estão as bases daquilo que se denominou como a participação pretendida pela terceira via e terceiro setor na lógica do público não-estatal. Em tal lógica, o ensino está sendo destituído da pedagogia da contestação, da transformação (grifos das autoras).

O terceiro setor, por ser composto por instituições de caráter privado sem fins lucrativos, constitui-se em empresas administradas com a lógica do setor privado, porém, com finalidades de interesse público. Segundo Franco (1999), essas empresas representam a sociedade civil no processo de reforma do Estado. Dessa forma,

[...] o que caracteriza a sociedade civil não são os legítimos interesses particulares ou setoriais nela situados e sim um novo 'interesse' público social que vai se compondo a partir do protagonismo crescente de novos sujeitos que estão emergindo dentro do chamado Terceiro Setor. Esta é a grande novidade da época em que vivemos: a emersão de uma nova esfera pública não-estatal, cuja dinâmica será capaz de mediar uma nova relação entre Estado e Mercado e, enfim, entre o Estado e a Sociedade lato sensu (FRANCO, 1999, p. 278 grifos do autor).

As análises de Silva (2008) sobre a participação do terceiro setor na política social destacam que: 
Esses mecanismos de flexibilização, pelo fato de serem os grandes corresponsáveis pela abolição da "solidariedade coletiva", são constituidores da lógica do "salve-se quem puder", pois contribuem decisivamente para o acirramento do desemprego estrutural, a gradativa redução dos direitos sociais dos trabalhadores, o descrédito de tudo que é público e para a sacralização do mercado. Esse complexo panorama social, econômico e político incide sobre a base de representação do Estado, pois tais novas dinâmicas vêm se expandindo de forma crescente, sobretudo durante as últimas duas décadas do século passado, contribuindo para o arrefecimento dos espaços coletivos e participativos (SILVA, 2008, p. 198).

A EJA integra e responde a um conjunto de ações que se coadunam com as características fundamentais do modelo de desenvolvimento desigual de distribuição de riqueza e renda, o que caracteriza a organização do mundo capitalista atual do qual faz parte uma política social focal implementada por intermédio de parcerias.

Sobre a política social desenvolvida pelo Estado, Offe (1984) argumenta que:

\begin{abstract}
A política social não se limita a oferecer (de forma confiável, e evitando conflitos) prestações de serviços, sem os quais seria difícil imaginar a integração permanente de força de trabalho no sistema de trabalho assalariado. Ela também se encarrega de controlar o uso “adequado" de tais prestações. Isto é necessário já que, em vista do caráter repressivo do trabalho assalariado, parece óbvia a tendência para que o trabalhador procure retirar-se (temporariamente) do processo de trabalho, recorrendo aos serviços de seguro. A necessidade de controlar o acesso aos serviços se demonstra empiricamente pelas oscilações, dependentes da conjuntura econômica, do montante de pacientes, cujo crescimento - em épocas de pleno emprego - mostra que os trabalhadores fazem uso de sua posição de força relativa no mercado de trabalho, deixando de trabalhar passageiramente. [...] Assim, o que pode ser considerado um emprego "aceitável", com que um desempregado tem de concordar, antes de receber o salário-desemprego, é fixável em função do ciclo econômico (OFFE, 1984, p. 29-30).
\end{abstract}

Offe (1984, p. 22) analisa a política social como a representação de uma estratégia do Estado em integrar a força de trabalho na relação de emprego assalariado. Logo, a política social não surge de uma preocupação do Estado em solucionar os problemas dos trabalhadores, mas sim contribui para "regulamentar o processo de proletarização". Dessa maneira, constata-se que a forma de existência do trabalho assalariado passa a ser preservada pela política social.

O caso da EJA no Brasil é um exemplo típico de política social, em que as ações governamentais são realizadas não apenas pelo Ministério da Educação (principalmente as ações ligadas às secretarias municipais e estaduais de educação, dependendo das prioridades de cada administração), mas também realizada por outros ministérios visando à educação profissional. Os cursos oferecidos foram "[...] de nível básico, em geral com cursos instrumentais, de curta duração e desvinculados da escolaridade a uma parcela significativa das frações mais fragilizadas da classe trabalhadora" (RUMMERT; VENTURA, 2007, p. 33). 
Dessa forma, os programas e projetos desenvolvidos pela sociedade civil para a EJA apresentam iniciativas vinculadas às representações de empresários, ou seja, o Sistema $\mathrm{S}$, Telecurso 2000; ao movimento sindical, com ações desenvolvidas por centrais, confederações e sindicatos; além de ações visando à escolarização de jovens e adultos desenvolvidas em parceria com diferentes grupos de atores sociais, que têm como discurso a valorização e o respeito dos direitos humanos aos processos de desenvolvimento. Mesmo que a maior parte das parcerias tenha origem em um movimento político de voluntariado, participação e educação popular, os interesses das organizações não governamentais foram convergentes com o intuito dos governos de baratear os custos dos serviços de educação de jovens e adultos.

Em síntese, a configuração da oferta da EJA no Brasil, a partir dos anos 1990, está inscrita em um processo mais amplo de reordenamento do papel do Estado, ou seja, é um exemplo de política social em que as ações governamentais foram realizadas não apenas pelo Ministério da Educação, mas também pelo Ministério do Desenvolvimento Agrário e pelo Ministério do Trabalho e Emprego.

Dessa forma, o objetivo de racionalizar os recursos e diminuir a participação do Estado indica que a política social "[...] deve ser repassada para a sociedade: para os neoliberais, por meio da privatização (mercado), e para a Terceira Via pelo público nãoestatal (sem fins lucrativos)" (PERONI e ADRIÃO, 2006, p. 14).

Um problema gerado pela falta de compromisso financeiro com a modalidade de ensino é a descaracterização da educação de jovens e adultos como modalidade que requer norma própria, projeto político-pedagógico específico e adequada formação de educadores.

\section{FINANCIAMENTO PARA A EJA NA LEGISLAÇÃO BRASILEIRA}

O financiamento da educação pública no Brasil possui fontes estabelecidas, previstas no Art. 212 da Constituição Federal de 1988, quais sejam: 25\%, no mínimo, proveniente das receitas de impostos e transferências dos estados, Distrito Federal e municípios, e nunca menos de $18 \%$ das receitas decorrentes de impostos da União.

Da mesma maneira, a Lei de Diretrizes e Bases da Educação Nacional (LDBEN) n ${ }^{\circ}$ 9.394/96, no seu Art. 68, destaca as fontes dos recursos destinados à educação, que são: receita de impostos próprios da União, dos estados, do Distrito Federal e dos municípios; receita de transferências constitucionais e outras transferências; receita do salário-educação e de outras contribuições sociais; receita de incentivos fiscais e outros recursos previstos em lei. 
A implementação das políticas públicas de educação de jovens e adultos é fortemente condicionada pelo financiamento atribuído a esse ensino. A oferta mínima e a precária qualidade da educação de jovens e adultos no Brasil podem ser justificadas pelo fato de que, em nenhum momento da história da educação brasileira, a EJA recebeu aporte financeiro significativo, embora em alguns períodos as políticas para o setor tenham se beneficiado de recursos vinculados ou fonte própria de financiamento, traduzindo a posição marginal que a modalidade de ensino ocupa na agenda governamental.

A reforma educacional iniciada em 1995 é um exemplo da marginalização da EJA quanto ao financiamento. Foi implementada sob o discurso de restrição do gasto público, a fim de cooperar com o modelo de ajuste estrutural e a política de estabilização econômica adotados pelo governo federal, mantendo a EJA na posição de exclusão que já vinha ocupando nas políticas públicas de âmbito nacional, reforçando as tendências à descentralização do financiamento e da produção dos serviços (HADDAD; DI PIERRO, 2000, p. 122).

Segundo Ventura (2001), a criação do Fundo de Manutenção e Desenvolvimento do Ensino Fundamental e Valorização do Magistério (Fundef) pela Lei n ${ }^{\circ}$ 9.424, sancionada em dezembro de 1996, foi um aspecto que acentuou a exclusão da EJA. Os alunos matriculados nessa modalidade não puderam ser considerados na contagem do censo geral, logo não podiam usufruir dos recursos do Fundo, sob a alegação de que haveria dificuldade de recenseamento e não disponibilidade de dados estatísticos no Instituto Nacional de Estudos e Pesquisas Educacionais (Inep).

Haddad e Di Pierro (2000) reforçam a informação:

\begin{abstract}
A operacionalização do dispositivo constitucional que criou o Fundef exigiu regulamentação adicional. Embora tenha sido aprovada por unanimidade do Congresso, a Lei 9.424/96 recebeu vetos do presidente, um dos quais impediu que as matrículas registradas no ensino fundamental presencial de jovens e adultos fossem computadas para efeito dos cálculos dos fundos, medida que focalizou o investimento público no ensino de crianças e adolescentes de 7 a 14 anos e desestimulou o setor público a expandir o ensino fundamental de jovens e adultos (HADDAD; DI PIERRO, 2000 p.123).
\end{abstract}

É nessa escassez de recursos para o financiamento da educação de jovens e adultos que a suplementação da União aos estados e municípios, em programas especiais dos diversos ministérios, adquire especial relevância, mesmo quando as quantias transferidas são de pequeno porte. Esse fato também impulsiona o governo a adotar estratégias de parceria, que atraem a colaboração de organizações da sociedade civil, tais como empresas, ONGs, sindicatos representativos dos trabalhadores, Sistemas S (Sesi, Senac, Senai, Sesc), para a implementação dos programas e projetos de educação de jovens e adultos.

O Fundef não incluiu a EJA nos recursos financeiros. O apoio financeiro aos estados e aos municípios, na área da EJA, foi fornecido por meio do Fundo Nacional de 
Desenvolvimento Educacional (FNDE), enquanto a Coordenadoria de Educação de Jovens e Adultos (Coeja) ficou responsável pelos materiais didáticos e implementação do programa de formação de educadores das redes estaduais e municipais.

Uma forma utilizada pelas secretarias de educação (estadual e municipal) para ocultar a ausência de recursos financeiros e computar as matrículas de alunos que se destinavam à modalidade da EJA foi o falseamento das estatísticas, declarando-se, no censo escolar, as matrículas na educação de jovens e adultos como ensino regular em programas de correção de fluxo escolar, conhecida como classes de aceleração para estudantes com defasagem sérieidade, modalidade esta passível de captação de recursos dos fundos (DI PIERRO, 2005).

Observa-se, assim, que a modalidade de ensino de jovens e adultos passou a ser compreendida como política compensatória e coadjuvante no combate às situações de extrema pobreza, cuja amplitude pode estar condicionada às oscilações dos recursos doados pela sociedade civil. A modalidade de ensino perdeu representação no atendimento educacional público e ainda ficou ausente de uma política articulada que pudesse atender de modo planejado ao grande desafio de superar o analfabetismo e elevar a escolaridade da maioria da população (HADDAD; DI PIERRO, 2000).

Na concepção de Andrade (2004, p. 49), o tratamento dado para essa situação, de forma fragmentada, faz com que o aluno se torne "socialmente invisível frente ao sistema escolar", ainda que a EJA seja uma alternativa para a escolarização tardia.

Para Rummert e Ventura (2007, p. 33) a EJA

\begin{abstract}
Passa a apresentar-se de forma mais ampla, mais fragmentada e mais heterogênea. Tais características, entretanto, não alteram sua marca histórica: ser uma educação política e pedagogicamente frágil, fortemente marcada pelo aligeiramento, destinada, predominantemente, à correção de fluxo e à redução de indicadores de baixa escolaridade e não à efetiva socialização das bases do conhecimento. E comprometida com a permanente construção e manutenção da hegemonia inerente às necessidades de sociabilidade do próprio capital e não com a emancipação da classe trabalhadora.
\end{abstract}

Em outro estudo, Rummert (2008) argumenta que a concepção de emancipação tem base na perspectiva do materialismo histórico, particularmente, nas reflexões de Marx (1989), que estabelece em uma das suas primeiras obras, A questão judaica, que "a emancipação humana requer que os homens se reconheçam, para além de suas individualidades, como forças sociais aptas a promover mudanças estruturais na sociedade" (RUMMERT, 2008, p. 188).

Mesmo com a criação do Fundo de Manutenção e Desenvolvimento da Educação Básica e de Valorização dos Profissionais da Educação (Fundeb) pela Emenda Constitucional de $n^{\circ} 53 / 2006$, regulamentada pela Lei $n^{\circ} 11.494 / 2007$, que passou a incluir a EJA no cômputo das matrículas consideradas para efeito de distribuição de recursos, após dez anos de 
atraso em relação ao Fundo de Manutenção e Desenvolvimento do Ensino Fundamental e Valorização do Magistério (Fundef), o fator de ponderação atribuído a EJA ainda foi o menor das outras modalidades de ensino do Fundo de Manutenção e Desenvolvimento da Educação Básica e de Valorização dos Profissionais da Educação (Fundeb). O fator de ponderação destinado à EJA $(0,7)$ não permite cobrir as despesas totais com a manutenção e desenvolvimento de um ensino de qualidade, mecanismo que tende a inibir a expansão das matrículas.

Sobre o Fundeb, Haddad e Ximenes (2008, p. 146) afirmam que, além de elevar a subvinculação para a educação básica nos estados, municípios e Distrito Federal, também "aumenta a participação financeira da União na manutenção desse nível, o que havia sido relegado desde 1996 com a edição da já referida Emenda n 14/1996”. Dessa forma, a EJA ainda tem passado por limitações quando se refere à regulamentação do Fundeb, principalmente no que diz respeito à ponderação dos valores assegurados por esse Fundo porque

[...], sendo a EJA, dentre todas as etapas e modalidades, a que receberá o menor valor anual por aluno, limitado a 0,70 (centavos), sendo que o fator 1,00 equivale às séries iniciais do ensino fundamental urbano. O ensino médio urbano, por exemplo, tem valor 1,20 (hum real e vinte centavos), ou seja, quase o dobro da EJA (Resolução MEC nº 01/2007) (HADDAD; XIMENES, 2008, p. 146 grifos nosso).

Isso reforça que a EJA passou de excluída do financiamento no Fundef para reconhecida no Fundo de Manutenção e Desenvolvimento da Educação Básica e de Valorização dos Profissionais da Educação (Fundeb), como a modalidade que recebe um percentual inferior em relação aos ensinos fundamental e médio. Mas a simples garantia de uma fonte regular de financiamento (com um valor mínimo por aluno que em 2007 variava de $\mathrm{R} \$ 662,40$ a $\mathrm{R} \$ 1.433,60$, dependendo da Unidade da Federação) abriu novas perspectivas para as políticas públicas de EJA.

Para Rummert e Ventura (2007, p. 41-42):

O reconhecimento da EJA como modalidade de educação básica ganha espaço no plano formal, porém isto não tem sido traduzido no plano político concreto. Embora dados apresentados pelo MEC apontem para a ampliação do atendimento e para os aumentos no orçamento do MEC para EJA, a atuação do Governo Federal continua predominantemente centrada nos números grandiosos de um programa como o Brasil Alfabetizado, cujos resultados estão, como vimos, longe do anunciado. Essa constatação aponta para o fato de que não dispomos, até hoje, de políticas que superem ações de governo implementadas a partir de objetivos e critérios discutíveis e se consolidem como políticas de Estado. Estão, assim, longe de serem atingidos objetivos como a superação de déficits quantitativos e qualitativos da EJA nas redes públicas, bem como da necessária isonomia no que tange ao financiamento público das diversas modalidades e etapas da educação básica.

$\mathrm{Na}$ maioria, os programas e projetos para a EJA desenvolvidos atualmente trazem uma visão pouco pedagógica, ou seja, ministram-se noções de informática e ação comunitária (como o Programa Nacional de Inclusão de Jovens - Projovem e o Programa Nacional de Integração da Educação Profissional com a Educação Básica na Modalidade de Educação de 
Jovens e Adultos - Proeja), o que limita o processo de alfabetização ao mero domínio do sistema de escrita e/ou elevação da escolaridade. Muitos dos programas espelharam-se no modo como tradicionalmente a escola funciona e promovem o ensino de modo semelhante às campanhas de alfabetização de curta duração, desarticuladas de outros programas nos quais jovens e adultos possam dar continuidade ao processo de aprendizagem.

De acordo com a historicidade da EJA ao longo dos anos, foi possível verificar a lógica que se oculta nas ideias de democratização dos programas e projetos implementados como acesso ao conhecimento. Conforme análise de Rummert (2008):

[...] a EJA se mostra num cenário em que são camufladas as razões estruturais dos diferentes processos de destituição de direitos da classe trabalhadora, agora conceitualmente fragmentada em diversos grupos focais, o que obscurece a existência dessa classe como tal. É obscurecido, também, por meio de falsos discursos de universalização de acesso e de democratização de "oportunidades", o direcionamento dos jovens e adultos com pouca ou nenhuma escolarização para diferentes ofertas de elevação de escolaridade que corroboram a atual divisão social do trabalho. Tal processo, apesar de seu desenho contemporâneo, não foge às clássicas estratégias de distribuição desigual e precária de fragmentos de conhecimento, subordinadas às demandas de distintos níveis de qualificação da força de trabalho requeridos pelos diferentes padrões produtivos que coexistem no País, bem como às necessidades de controle social (RUMMERT, 2008, p. 176).

Paiva (2006) considera que não é a ausência de leis que colaboram para o não cumprimento dos direitos expressos por meio de pareceres e resoluções mas,

[...] o contexto em que se promove e se defende esse direito é fortemente desigual, produtor de exclusões, porque o mundo em que é reivindicado se rege pela ideologia do capital, para o qual a desigualdade é fundamento, e não a equidade (PAIVA, 2006, p. 256).

Isso, de certa forma, reflete "o caráter de amenização das tensões sociais e dos impasses inerentes à lógica do sistema sendo cumpridas por diferentes programas" (RUMMERT e VENTURA, 2007, p. 40). A ideia que se apreendeu nesse artigo foi a de que as parcerias entre governos municipais e ONGs com o governo federal resultaram em iniciativas locais, sem o comprometimento com uma política pública universal para a EJA, mesmo recebendo a transferência de recursos financeiros para a implementação dos projetos e programas.

\section{CONSIDERAÇÕES FINAIS}

As discussões trazidas nesta pesquisa, que é o recorte de um trabalho mais amplo já concluído em tese de doutoramento, permitiram apreender a relação entre Estado e sociedade civil nas políticas educacionais para a EJA, apontando a atuação das organizações não governamentais na oferta e no acompanhamento dessa modalidade, com recebimento de 
repasse de recursos públicos, pelo intermédio das parcerias e assinaturas de convênios, justificando uma suposta ‘impossibilidade do Estado’ de atender à demanda.

Isso significou que diversos órgãos do governo federal, estadual e municipal viabilizaram parcerias com empresas e com organizações da sociedade civil para a realização de diversos serviços públicos de interesse da sociedade, especialmente nas áreas da educação, da saúde e da assistência social, serviços que antes eram executados exclusivamente pelo Estado, como políticas de governo ou mesmo como políticas de Estado.

As parcerias realizadas entre as organizações da sociedade civil e o Estado são apresentadas nas implementações dos programas e projetos para a EJA, destacando certa ambiguidade: enquanto transferem a responsabilidade pela garantia de direitos universais para a sociedade civil, também canalizam a contribuição da sociedade organizada para a universalização da alfabetização e democratização da educação de jovens e adultos, ampliando os canais de controle social sobre as ações governamentais (DI PIERRO, 2004, p. 20). Se, antes, a participação da sociedade civil se circunscrevia aos processos de democratização do Estado, pelo seu papel de controle e direcionamento dos serviços públicos, neste momento ela é conduzida a colaborar diretamente com a oferta dos serviços educacionais, na lógica de diminuição das responsabilidades do Estado.

A presença do capital no plano das ações sociais e da educação, em particular, demonstra duas faces contraditórias. Por um lado, aponta para um importante compromisso social de parte do capital, em países como o Brasil, com elevada concentração de renda e considerável desnível social. Por outro lado, aponta também para um crescente descomprometimento do setor público com a educação, correndo-se o risco de rompimento de um dos aspectos mais importantes na construção da democracia social brasileira.

\section{REFERÊNCIAS}

ANDRADE, Eliane Ribeiro. Os jovens da EJA e a EJA dos jovens. In: OLIVEIRA, Inês Barbosa; PAIVA, Jane. (Orgs.). Educação de jovens e adultos. Rio de Janeiro: DP\&A, 2004.

BRASIL. Lei de diretrizes e bases nacionais de educação (LDBEN) 9.394/96. Brasília, DF: Senado Federal, 1996.

BRASIL. Resolução/MEC n⿳0 01 de 15.02.2007. Estabelece fatores de ponderação aplicáveis à distribuição dos recursos do FUNDEB. Brasília, DF: Senado Federal, 2007. 
DELUIZ, Neise; GONZALEZ, Wânia Regina Coutinho; NOVICKI, Victor. Sociedade civil e as políticas de educação de jovens e adultos: a atuação das ONGs no Rio de Janeiro. In: REUNIÃO ANUAL DA ANPED, 28., 2005, Caxambu, Anais.... Caxambu/MG: ANPED, 2005.

DI PIERRO, Maria Clara. Visões da educação de jovens e adultos no Brasil. Campinas, SP: Cadernos Cedes, ano XXI, n.55, p. 58-77, nov. 2001.

DI PIERRO, Maria Clara. Um balanço da evolução recente da educação de jovens e adultos no Brasil. Alfabetização e Cidadania. Revista de Educação de Jovens e Adultos, $\mathrm{n}^{\circ}$ 17, 2004.

DI PIERRO, Maria Clara. Notas sobre a redefinição da identidade e das políticas públicas de educação de jovens e adultos no Brasil. In: Revista Educação e Sociedade, v. 26, n. 92, p. 1115-1139, 2005.

FRANCO, Augusto. A reforma do Estado e o terceiro setor. In: BRESSER PEREIRA, Luiz Carlos; WILHEIM, Jorge; SOLA, Lourdes (Ed.) Sociedade e estado em transformação. São Paulo: Ed. da UNESP; Brasília, DF: ENAP, 1999. p. 273-289.

HADDAD, Sérgio e DI PIERRO, Maria Clara. Escolarização de jovens e adultos. Revista Brasileira de Educação, São Paulo, Anped, nº. 14, p. 108-130, maio /ago., 2000.

HADDAD, Sérgio e XIMENES, Salomão. A educação de pessoas jovens e adultas e a nova LDB: um olhar passados dez anos. In: BRZEZINSKI, Iria (Org.). LDB dez anos depois: reinterpretação sob diversos olhares São Paulo: Cortez, 2008.

MÉSZÁROS, István. O desafio e o fardo do tempo presente. São Paulo: Boitempo, 2007.

MONTAÑO, Carlos. Terceiro setor e a questão social: crítica ao padrão emergente de intervenção social. 2. ed. São Paulo: Cortez, 2002.

OFFE, Clauss. Problemas estruturais do estado capitalista. Rio de Janeiro: Tempo Brasileiro, 1984.

OLIVEIRA, Francisco de. O surgimento do antivalor. In: Novos Estudos, São Paulo: CEBRAP, 1988.

PAIVA, Jane. Tramando concepções e sentidos para redizer o direito à educação de jovens e adultos. Revista Brasileira de Educação, v.11, n. 33. p. 519-566, set./dez., 2006.

PERONI, Vera Maria; OLIVEIRA, Regina Tereza Cestari de; FERNANDES, Maria Dilnéia Espíndola. O Estado e o terceiro setor: as novas regulações entre o público e o privado na 
gestão da educação básica brasileira. Educação e Sociedade. Campinas, SP, v. 30, n.108, p. 761- 778, out. 2009.

PERONI, Vera Maria.; ADRIÃO, Theresa. Mudanças na configuração do Estado e sua influência na política educacional. In: PERONI, V.; BAZZO, V.L.; PEGORARO, L. (Org.). Dilemas da educação brasileira em tempos de globalização neoliberal: entre o público e o privado. Porto Alegre: UFRGS, 2006. p. 11-23.

RUMMERT, Sonia Maria. Educação de jovens e adultos trabalhadores no Brasil atual: do simulacro à emancipação. Revista Perspectiva, Florianópolis, v. 26, n. 1, 175-208, jan./jun. 2008.

RUMMERT, Sônia Maria; VENTURA, Jaqueline Pereira. A educação de jovens e adultos trabalhadores brasileiros no século XXI. O "novo" que reitera antiga destituição de direitos. Revista Educar, Curitiba, n. 29, p. 29-45, 2007.

SILVA, Maria Vieira. O estado e o mundo do trabalho em mutação: reflexões sobre a relação entre a esfera pública e privada no âmbito do terceiro setor. IN: LUCENA, Carlos. (Org.). Capitalismo, estado e educação. Campinas, SP: Editora Alínea, 2008.

ALFABETIZAÇÃO de jovens e adultos no Brasil: lições da prática. Brasília, DF: UNESCO, 2008.

VENTURA, Jaqueline Pereira. O PLANFOR e a educação de jovens e adultos trabalhadores: a subalternidade reiterada. 2001. Dissertação (Mestrado em Educação) Universidade Federal Fluminense, Niterói, RJ 2001.

Como citar este documento:

MAIOLINO, Elielma Souza. Relação estado e sociedade civil nas políticas educacionais para a educação de jovens e adultos. ETD - Educação Temática Digital, Campinas, SP, v. 17, n. 1, p. 75-87, jan./abr. 2015. ISSN 1676-2592. Disponível em: <https://www.fe.unicamp.br/revistas/ged/etd/article/view/6894>. Acesso em: 29 abr. 2015. 